\title{
Unscarred Uterine Rupture: A Retrospective Analysis
}

\author{
Manisha Vernekar ${ }^{1,2} \cdot$ Roy Rajib ${ }^{1}$
}

Received: 1 March 2015/Accepted: 13 August 2015/Published online: 8 September 2015

(C) Federation of Obstetric \& Gynecological Societies of India 2015

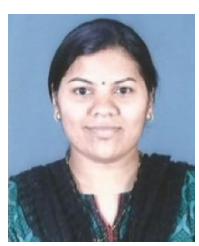

\begin{abstract}
About the Author
Manisha Vernekar is currently working as a Senior Resident in the Department of Obstetrics and Gynaecology, ESIPGIMSR, ESIC \& MC, Joka, Kolkata. She completed her MBBS in 2009, from Goa Medical College, Goa, and M.S. (OBGY) in 2013, from the Regional Institute of Medical Sciences, Imphal. She has presented free papers at state, regional, national (55th, AICOG, Varanasi), and international (XX, FIGO World Congress, 2012, Rome) levels during her post graduation. Her paper abstract entitled "Female Feticide in India: The Missing Girl child" was published in Journal International de Medicine. Her fields of interest are laparoscopy and infertility. She got the "best poster" prize for this paper.
\end{abstract}

\begin{abstract}
Introduction Uterine rupture is a catastrophic obstetrical emergency associated with a significant feto-maternal morbidity and mortality. Many risk factors for uterine rupture, as well as a wide range of clinical presentations, have been identified.
\end{abstract}

Manisha Vernekar is a Senior Resident; Roy Rajib is an Assistant Professor in the Department of Obstetrics \& Gynaecology, ESIPGIMSR, ESIC \& MC, Kolkata, India.

Manisha Vernekar

manu_1486@yahoo.co.in

1 Department of Obstetrics \& Gynaecology, ESI-PGIMSR, ESIC \& MC, Joka, Kolkata, India

2 c/o Dr Rajib Roy, Plot No 34/1, Pailan Park Housing Project, Pailan, Mouza Daulatpur, P.S-Bishnupur, Kolkata 700104, India
Objectives To analyze the frequency, predisposing factors, and maternal and fetal outcomes of uterine rupture.

Methods A retrospective analysis of cases of unscarred uterine rupture was conducted at the Department of Obstetrics and Gynecology, RIMS, Imphal from June 1, 2010 to June 30, 2012.

Results Our analysis comprised 13 cases. Of these, $30.8 \%$ were booked cases. Most of the cases (46.2\%) were Para 2. Uterine rupture occurred at term in 10 cases. The rupture occurred due to mismanaged labor $(30.8 \%)$, the use of oxytocin (23\%), instrumental delivery (15.4\%), obstructed labor $(15.4 \%)$, induction by prostaglandin gel $(7.7 \%)$, and placenta percreta $(7.7 \%)$. Maternal deaths and perinatal deaths were 30.8 and $53.8 \%$, respectively. Sub-total hysterectomy was done in 8 cases and in 1 patient laparotomy with repair was performed.

Conclusion Ruptured uterus causes a high risk in patients. An unscarred uterus can undergo rupture even without etiological or risk factors. The patients with 
mismanaged labor, grand multiparas, and obstructed prolonged labor must be managed by properly trained personnel at a tertiary care center in order to avoid the morbidity or mortality.

Keywords Uterine rupture - Unscarred uterine rupture . Obstructed labor - Induction of labor .

Instrumental delivery

\section{Introduction}

Uterine rupture is a life-threatening event in a woman's life. It may not only endanger her life but also may even affect her future fertility status as well [1].

This is a catastrophic complication of pregnancy and labor associated with a high incidence of fetal and maternal morbidity and mortality [2]. Maternal mortality ranges between 1 and $13 \%$ and perinatal mortality between 74 and $92 \%$ [3].

The key factor of uterine rupture is the presence of scar. The normal, unscarred uterus is least susceptible to rupture. Spontaneous rupture of an unscarred uterus during pregnancy is a rare occurrence and is usually traumatic, and its incidence decreases with improvement in obstetric practice. However, its incidence remains high in developing countries [4].

The major risk factors in unscarred uterine rupture are obstructed labor, high parity, placenta percreta, injudicious use of uterotonic drugs, and rarely intrauterine manipulations such as internal podalic version and breech extraction [3]. Most cases present with maternal tachycardia, signs of fetal distress, and bleeding per vagina [5].

Several factors are known to increase the risk of uterine rupture, and these include poor socioeconomic conditions, uncontrolled fertility, illiteracy, adolescent marriages, and underdeveloped and contracted pelvis [2].

Spontaneous uterine rupture is associated with highly variable and nonspecific maternal complaints and fetal status, requiring a high index of diagnostic suspicion [6].

Maternal and perinatal outcomes are optimized by awareness of risk factors, recognition of clinical signs and symptoms, and prompt surgical intervention [7].

The present study is aimed at establishing the frequency of ruptured uterus in our hospital and identifying the possible etiological factors and also the ways to improve the feto-maternal outcome in unscarred uterine rupture.

\section{Aims and Objectives}

- To analyze the frequency and predisposing factors of unscarred uterine rupture

- To determine maternal and perinatal outcomes.

\section{Methods}

A retrospective analysis of unscarred uterine rupture cases was conducted at the Department of Obstetrics and Gynecology, Regional Institute of Medical Sciences, Imphal, from June 1, 2010 to June 30, 2012. All cases of uterine rupture without any previous scar or any other previous uterine operation were included. The age, parity, risk factors, causes of rupture, and feto-maternal outcome were analyzed using descriptive statistics like mean, standard deviation, and percentages. The data were analyzed using SPSS 16. For this type of study, formal consent is not required.

\section{Results}

Our case series comprised 13 cases of rupture in unscarred uterus. The total number of deliveries during the study period was 22,950 giving an incidence of $0.057 \%$. The mean age of the women was $32.31 \pm 4.151$ years with an age range of 27-39 years. In our review, 9 (69.2\%) cases were unbooked, most of them referred from peripheral health centers, and only 4 (30.8\%) were booked cases. Table 1 shows the distribution of number of referred cases.

Most of the women were in obstetric shock on arrival at the hospital. Of 13 cases, 10 (76.9\%) were of term pregnancies, whereas $3(23.1 \%)$ were preterm. In our study, 8 $(61.5 \%)$ women were managed at the hospital during labor, whereas $5(38.5 \%)$ women were managed at home. The maximum duration of labor was $20 \mathrm{~h}$ as seen in one woman. Majority of women (76.9\%) were in their second stage of labor when they reached the hospital. In our series, six women $(46.2 \%)$ had laparotomy within $2 \mathrm{~h}$ of admission. The highest number of rupture was seen among Para 2 (46.2 \%), followed by Para 1 (30.8\%), Para $5(15.4 \%)$, and Para $3(7.7 \%)$, respectively. Mismanaged labor at home by traditional birth attendant was found to be the major risk factor. The causes of uterine rupture are shown in Table 2. Women presented with signs and symptoms which are shown in Table 3. The rupture was classified according to the site involved (Fig. 1). There were four maternal deaths $(30.8 \%)$ out of which one died within $30 \mathrm{~min}$ after laparotomy. In our study, four cases required Intensive Care Unit (ICU) admission with maximum stay of 8 days. Sub-total hysterectomy was performed in 8

Table 1 Distribution of referred cases $(n=13)$

\begin{tabular}{lcl}
\hline Referred cases & Number & Percentage \\
\hline No & 7 & 53.8 \\
Yes & 6 & 46.2 \\
Total & 13 & 100 \\
\hline
\end{tabular}


Table 2 Causes of unscarred uterine rupture $(n=13)$

\begin{tabular}{lcl}
\hline Causes & No. of cases & Percentage \\
\hline Mismanaged labor & 4 & 30.8 \\
Use of oxytocin & 3 & 23.0 \\
Instrumental delivery & 2 & 15.4 \\
Obstructed labor & 2 & 15.4 \\
Prostaglandin gel induction & 1 & 7.7 \\
Placenta percreta & 1 & 7.7 \\
Total & 13 & 100 \\
\hline
\end{tabular}

Table 3 Signs and symptoms presented $(n=13)$

\begin{tabular}{lll}
\hline Signs & No. of cases & Percentage \\
\hline Absent fetal heart rate & 7 & 53.84 \\
Loss of uterine contractility & 6 & 46.15 \\
Vaginal bleeding & 6 & 46.15 \\
Shock & 9 & 69.23 \\
\hline
\end{tabular}

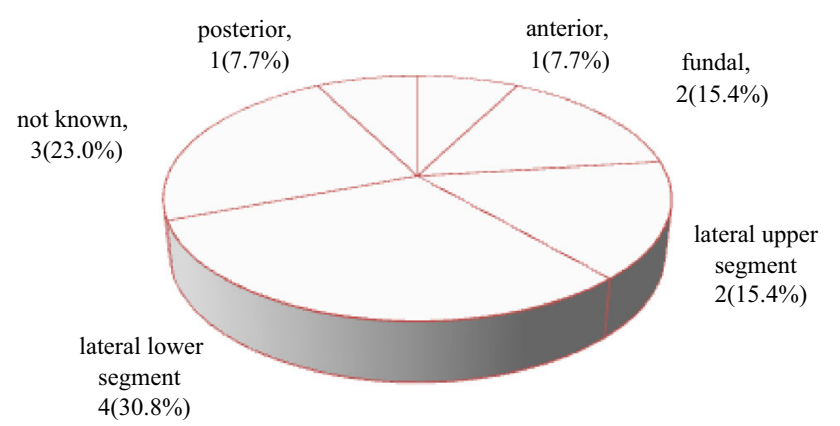

Fig. 1 Site of uterine rupture

women $(66.7 \%)$. In one woman, laparotomy and repair of rupture along with tubal ligation were performed. The overall hospital stay of the women was found to be 8-10 days. The perinatal mortality attributable to uterine rupture was $53.8 \%$.

\section{Discussion}

Uterine rupture during pregnancy is a rare occurrence that frequently results in life-threatening maternal and fetal complications. Its incidence is reported to be $0.012 \%$ [8].

With ready access to obstetric care including cesarean section for obstructed labor, rupture of the unscarred uterus in contemporary to obstetric practice should be rare [5]. If a gravid woman presents with hypotension, abdominal pain, fetal distress, and vaginal bleeding, rupture uterus should be suspected [6].
The frequency of uterine rupture in the present study was $0.057 \%$ which is higher than that in a study done by Ahmadi et al. [9], who had a figure of $0.038 \%$. However, only single report from a developed country gave a prevalence of $0.006 \%$ for women without previous cesarean section [3]. Most of the women in this study were in the age group of 27-39 years with the mean age of $32.31 \pm 4.15$ years.

Among the women in this series, the lack of antenatal care was strikingly frequent $(69.2 \%)$ and is comparable with that of Rashmi et al. [10] where it was $80 \%$. Majority of the rupture occurred in Para 2 which is similar to the findings by Rizwan et al. [2].

Most of the rupture occurred in the second stage of labor (76.9\%), and in only $23.1 \%$ it occurred before the initiation of labor which is comparable to the study as reported by Nahum [8] (86 and $14 \%$, respectively).

The most common site of rupture was in the lower uterine segment $(30.8 \%)$, contrary to the findings of the study done by Rizwan et al. [2] in which $80 \%$ of the rupture was observed in the lower uterine segment.

Mismanaged labor, injudicious use of oxytocin, obstructed labor, instrumental delivery, prostaglandin gel induction, and placenta percreta were found to be the common risk factors which were similar to the findings of Miller et al. [7].

The increased risk of uterine rupture attributable to the use of oxytocin in multigravida with unscarred uteri is uncertain as proposed by Nahum et al. [8]. In our review, rupture following the use of oxytocin was found among three women $(23.1 \%)$, despite labor being managed in the peripheral hospital.

In one woman, the placenta percreta was the cause of uterine rupture. Similarly, unscarred uterine rupture secondary to placenta percreta was reported by Imseis et al. in 1998 [11] and Esmans et al. [12] in 2004.

In our review, there were 4 maternal deaths $(30.8 \%)$ which is higher than that reported by Ahmadi et al. [9] where it was $7.1 \%$. Maternal death occurred within 30 min after laparotomy in one case which was similar to a case report of Dane et al. [13] in 2009. In this study, perinatal mortality was $53.8 \%$ which was similar to the observation of Rashmi et al. (78.66\%) [10].

The rupture site involved mostly the lower segment, often across the lateral side. Sub-total hysterectomy was performed in $87.5 \%$ in our series due to extension to adjacent structures, causing difficulty in repairing the rupture, necessitating hysterectomy. The rate was found to be lower in a study by Ahmadi et al. (32.1\%) [9]. In our study, repair of the rupture uterine site was performed in a single woman. 


\section{Conclusion}

Unscarred uterine rupture is a relatively rare complication of the pregnancy. However, its incidence remains high in developing countries. This study concluded that mismanaged labor is the main cause of unscarred rupture uterus followed by injudicious use of oxytocin and obstructed labor. The women with mismanaged labor, grand multiparas, and obstructed labor must be managed by trained personnel at a tertiary care center in order to avoid high maternal and perinatal morbidity or mortality.

Funding Self

\section{Compliance with Ethical Standards}

Ethical clearance For this type of study, formal consent is not required. This article does not contain any studies with human participants performed by any of the authors.

Conflict of interest Manisha Vernekar and Rajib Roy declare that they have no conflict of interest.

\section{References}

1. Akhtar Y. Ruptured uterus; an on-going tragedy of motherhood. Prof Med J. 2010;17(2):314-7.
2. Rizwan N, Abbasi RM. Uterine rupture, frequency of cases and fetomaternal outcome. J Pak Med Assoc. 2011;61(4):322.

3. Justus Hofmeyr G, Say L, Metin Gülmezoglu A. WHO systematic review of maternal mortality and morbidity: the prevalence of uterine rupture. BJOG. 2005;112:1221-8.

4. Turner MJ. Uterine rupture. Best Pract Res Clin Obstet Gynaecol. 2012;16(1):69-79.

5. Mazzone ME, Woolever J. Uterine rupture in a patient with an unscarred uterus: a case study. WMJ. 2006;105(2):64-6.

6. Dow M, Wax JR, Pinette MG, et al. Third trimester uterine rupture without previous cesarean: a case series and review of the literature. Am J Perinatal. 2009;26(10):739-44.

7. Miller DA, Goodwin TM, Gherman RB, et al. Intrapartum rupture of the unscarred uterus. J Obstet Gynecol. 1997;89(5):671-3.

8. Nahum GG, Pham KQ. Uterine rupture in pregnancy. (Online) 2011 (Cited 2008 Jan 15). Available from URL http:// emedicine.medscape.com/article/275854.

9. Ahmadi S, Nouira M, Bibi M. Uterine rupture of the unscarred uterus. About 28 cases. Gynecol Obstet Fertil. 2003;31(9):713-7.

10. Rashmi, Radhakrishnan G, Vaid NB, et al. Rupture uteruschanging Indian scenario. J Indian Med Assoc. 2001;99(11): $634-7$.

11. Imseis HM, Murtha AP, Alexander KA, et al. Spontaneous rupture of a primigravid uterus secondary to placenta percreta: a case report. J Reprod Med. 1998;43(3):233-6.

12. Esmans A, Gerris J, Corthout E, et al. Placenta percreta causing rupture of an unscarred uterus at the end of the first trimester of pregnancy: case report. Hum Reprod. 2004;19(10):2401-3.

13. Dane B, Dane C. Maternal death after uterine rupture in an unscarred uterus: a case report. J Emerg Med. 2009;37(4):393-5. 